\title{
Spatio-temporal distribution and habitat preference of necrophagous Calliphoridae based on 160 real cases from Switzerland
}

\author{
Jiri Hodecek ${ }^{1,2}\left[\right.$ Pavel Jakubec $^{3}$
}

Received: 5 May 2021 / Accepted: 20 December 2021 / Published online: 22 January 2022

(C) The Author(s) 2022

\begin{abstract}
Necrophagous blowflies (Diptera: Calliphoridae) are of great importance particularly during investigations of suspicious deaths. Many studies have analyzed the distribution of blowflies based on pig experiments and baited trapping; however, data from real case scenarios are rarely used. In this article, the distribution of blowflies found during investigations of 160 real cases during 1993-2007 in Switzerland is evaluated based on habitat, altitude, and season. Ten species of blowflies were present in 145 out of the 160 cases. The most common species was Calliphora vicina, which occurs throughout the year and was present in $69 \%$ of all cases. Lucilia sericata, Calliphora vomitoria, and L. caesar were identified among the rest of the flies as species of great forensic importance mainly due to their distributional patterns. After a comparison with a similar dataset from Frankfurt, Germany, some surprising differences were determined and discussed. The biggest discrepancies between our dataset and the German dataset were in the occurrences of L. sericata (30\% vs. 86 \%, respectively), Phormia regina (5 $\%$ vs. $43 \%$ ), and L. ampullacea ( $1 \%$ vs. $45 \%$ ). The life-history strategies and intraspecific behavioral variability of blowflies remain understudied, although they can be essential for an unbiased approach during a death investigation. Further research and comparison of occurrence patterns across the area of distribution of blowflies are therefore needed and recommended.
\end{abstract}

Keywords Blowflies $\cdot$ Switzerland $\cdot$ Altitude $\cdot$ Real cases $\cdot$ Investigation $\cdot$ Forensic entomology

\section{Introduction}

The blowflies belong to the most important family of necrophagous Diptera used during forensic investigations. Species of this family are usually common, highly abundant and among the first colonizers of a dead body $[1,2]$. Their presence is mainly determined by the season (i.e., the annual phenology of particular species), habitat type (within the area of distribution of the species) and by the ambient temperature and microclimatic conditions at the death scene (i.e., the requirements of particular species to finish their life cycle) [3]. Therefore, every forensic entomologist needs

Jiri Hodecek

jiri.hodecek@chuv.ch

1 Swiss Human Institute of Forensic Taphonomy, University Centre of Legal Medicine, CH-1000 Lausanne, Switzerland

2 Musée Cantonal de Zoologie, Palais de Rumine, Place de la Riponne 6, CH-1014 Lausanne, Switzerland

3 Department of Ecology, Faculty of Environmental Sciences, Czech University of Life Sciences Prague, Kamýcká 129, CZ-165 00 Praha - Suchdol, Czech Republic to not only identify the focal species, but also to know their local spatio-temporal distribution and habitat preferences. This is particularly important in the case of the blowflies, as they are usually cosmopolitan species with not always consistent habitat association patterns. The patterns can change geographically depending on the local offer of the habitat types [4]. An example of such species is L. sericata, which can locally be a common species of open pastures $[5,6]$, while at the same time it is a common inhabitant of urban areas (often found in indoor cases) [7-9].

The common design of experiments, which aims to map the distribution and habitat preference of blowflies, often counts on baited traps usage (bottle traps, inverted cone traps, Schoenly traps) which attract the specimens by using different kinds of attractants [4, 10-14]. The bottle traps certainly can serve as a basic tool for monitoring of blowflies; however, the attractiveness depends on the type of bait used. Furthermore, such traps can induce biases, because they can be neglected or even avoided by certain species due to their preferred diet $[3,15-17]$ and care should be taken when extrapolating such results to case scenarios $[18,19]$. For example, $C$. vomitoria and Protophormia terraenovae 
are common blowflies, which can be often found on human corpses; however, they might avoid bottle traps, because they prefer a cadaver of a certain size [5, 20, 21]. These specific preferences of certain species can potentially bias such research and result in an under- or overestimation of abundance or even the presence of some of the focal species. Several studies focused on the distribution of blowflies using pig cadavers have already been published [21-24] and while such an approach is certainly more suitable (with pigs to be the most accurate option compared to human cadavers), there have not been many studies using the data of real cases to obtain such results [3, 25-27]. The reasons are probably (1) the size and time needed for obtaining a large enough dataset for making meaningful conclusions and (2) the legal complications stemming from the publication of such a sensitive dataset in some countries.

The data from real cases collected over long periods of time (ideally decades) are rarely published. Such dataset can however be extremely important for understanding the local fauna linked to real case scenarios in different geographic locations especially when forensic entomologists rely upon old and restricted taxonomic keys, which may not include all the local species [19]. The real case data are also irreplaceable for elucidation of the ecology, colonization patterns and spatio-temporal distribution of blowflies for indoor cases. Indoor cases represent a large portion of the casework during medico-legal investigations [3, 19, 26, 27]. Furthermore, indoor habitats have a completely different thermal dynamic in comparison to outdoor habitats and this dynamic differs based on local climatic conditions [19, 22]. Understanding local climatic conditions and how species at different habitats adapt to them can provide crucial information during investigations and the post-mortem interval $\left(\mathrm{PMI}_{\min }\right)$ estimations. However, it is nearly impossible to conduct such experimental study under controlled conditions due to possible health risk issues and financial constraints; therefore, the real case data represent a unique window allowing a closer look at the life of blowflies under such settings. In this article, an extensive dataset of blowflies built from 160 real cases over a period of 14 years (1993-2007) in Switzerland has been analyzed, along with their spatio-temporal distribution and habitat preference. This study enables comparisons with other forensic and ecological studies, particularly with respect to larger scale trends in insect colonization patterns.

\section{Material and methods}

The data comes from 160 criminal investigations involving entomological expertise, which were conducted in between the years of 1993-2007 in and around Lausanne in Switzerland [28]. The area includes canton of Vaud, canton of
Geneva, canton of Fribourg, canton of Valais, and canton of Ticino (Fig. 1).

The insects were collected by Claude Wyss, who was a forensic investigator and an enlightened amateur in forensic entomology, working for the police in the 1990s and early 2000s. The collection was performed mostly at the death scene, but sometimes also during the autopsy. The real proportion of the scene/autopsy sampling is not known. The sampling techniques used to collect the insect material are described in Cherix et al. (2012) [29]. Immature stages of blowflies (Calliphoridae) collected on corpses were reared in the laboratory under controlled conditions to the adult stage and later used for the post-mortem interval $\left(\mathrm{PMI}_{\min }\right)$ estimations. All collected insect material was mounted and stored in the Museum of Zoology in Lausanne. The blowflies were originally identified by Wyss, Cherix, and Faucherre based on their terminalia and relying on a combination of the identification keys and the reference collection at the Zoological Museum, University of Copenhagen [29]. The material was revised in 2019-2020 by Hodecek, who worked on the correction and actualization of the database (as many identifications were either wrong or missing). The revision of the family Calliphoridae was made based on the actualized available key by Szpila [30].

\section{Data management and statistical evaluation}

Species from family Calliphoridae with more than 5 records were selected for the analyses (i.e., Cynomia mortuorum with 2 records and Lucilia ampullacea with one record were excluded). We also made sure that the information regarding the date of discovery (month, year), habitat where the body was found, and an altitude were available. We worked only with living developmental stages, i.e., we did not include puparia or dead adults in our analyses. Unfortunately, we did not have information about the sex and age of the deceased, manner of death, and the $\mathrm{PMI}_{\min }$ for all the cases.

The original database we worked with contained a detailed description of the biotope for 115 cases. We were able to obtain the information about the habitats for the missing 45 cases thanks to the coordinates of the body localizations, which-altogether with public accessible historical satellite images of the places from Google Earth Pro (version 7.3.3.7786) [31] - gave us the basic type of the biotope necessary for our analyses. All the cases were divided into 6 biotope types-forest (all types), meadow (including pastures and grasslands), field (all types of agricultural areas such as vineyards or cornfields), alpine (high mountain area without vegetation), park (including gardens), and apartment (all indoor cases). The types of the habitat were then used as variables for canonical correspondence analysis (CCA) (Fig. 2). 


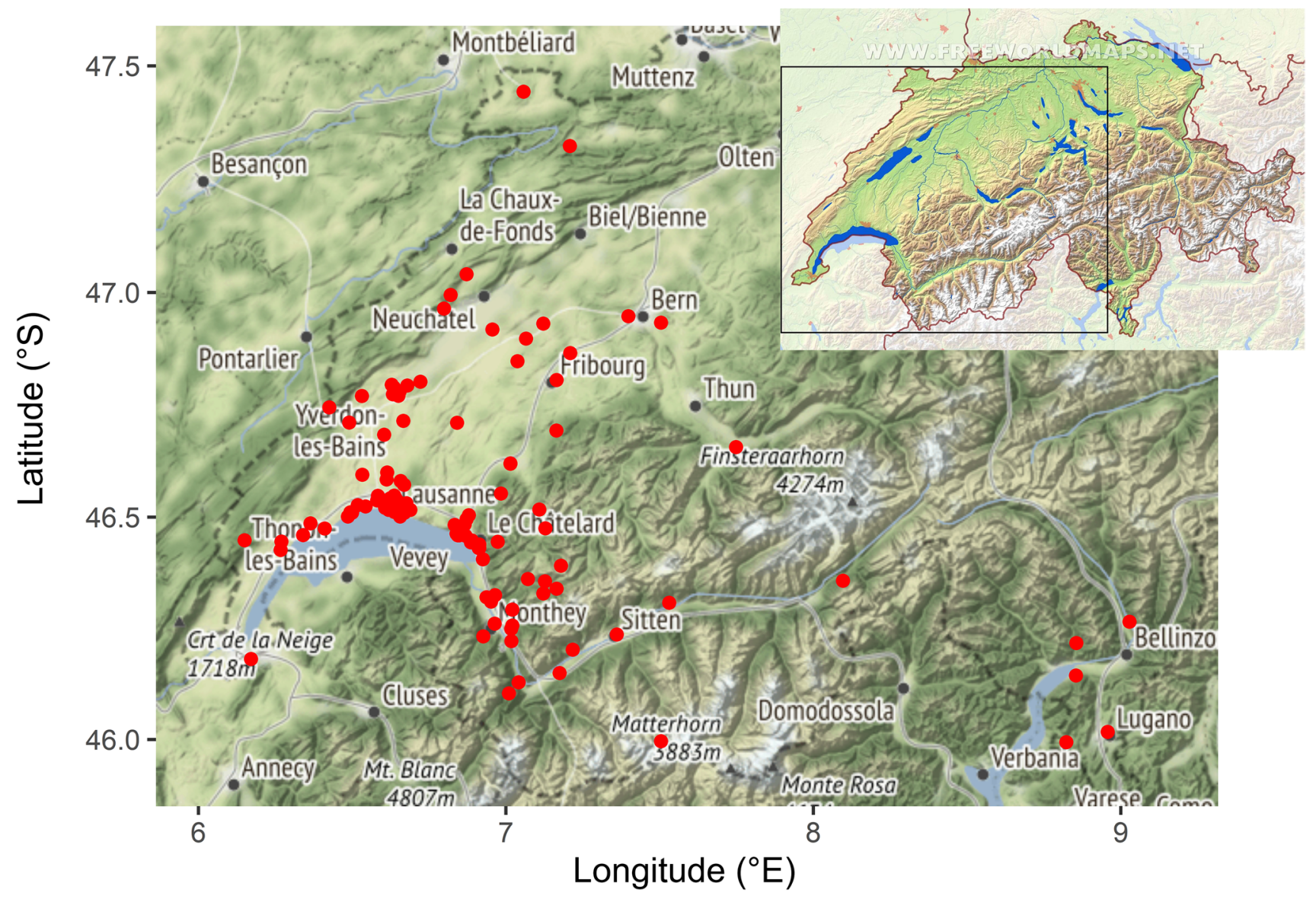

Fig. 1 The map of real case investigations in and around Lausanne during 1993-2007 (the map of Switzerland downloaded from www.freew orldmaps.net)

In order to visualize and test the relationships between the composition of the communities associated with human remains across continuous explanatory factor altitude and two discrete factors of season and habitat, the constrained CCA from R package vegan was used [32]. The significance of each environmental variable was tested by permutation tests with 9999 permutations to establish if the relationship was significantly affected by the factors in question, using anova.cca function from the package vegan as well [32].

The effect of altitude on the presence or absence of focal species was established using a binomial linear regression analysis with mixed effects (GLMM). The response variable was the presence/absence of the species and fixed effect explanatory variables were species' identity and the natural logarithm of altitude. As the random effect explanatory variable, we used months, to eliminate the season's effect. Furthermore, intercept and regression slope were allowed to vary between species, so they could be evaluated independently.
The significance levels in all analyses were set at 5\%. Data management and statistical evaluation were performed in $\mathrm{R}$ (version 4.0.3.) [33].

\section{Results}

Blowflies were present in 145 out of 160 real case investigations of dead bodies in our dataset, which is in concordance with the widespread image of blowflies being the most important family of necrophagous flies used for criminal investigations $[1,2]$. There was a clear pattern of seasonal distribution of the cases with a peak in summer and a gap in winter months (Fig. 3). Out of the 145 cases, 88 (i.e., $61 \%$ ) were located indoor. The most dominant species was C. vicina (100 cases-69\%), followed by L. sericata (44 cases-30\%), C. vomitoria (42 cases-29\%), and L. caesar (39 cases-27\%). In total, there were 10 species of blowflies present on the bodies (Table 1). 


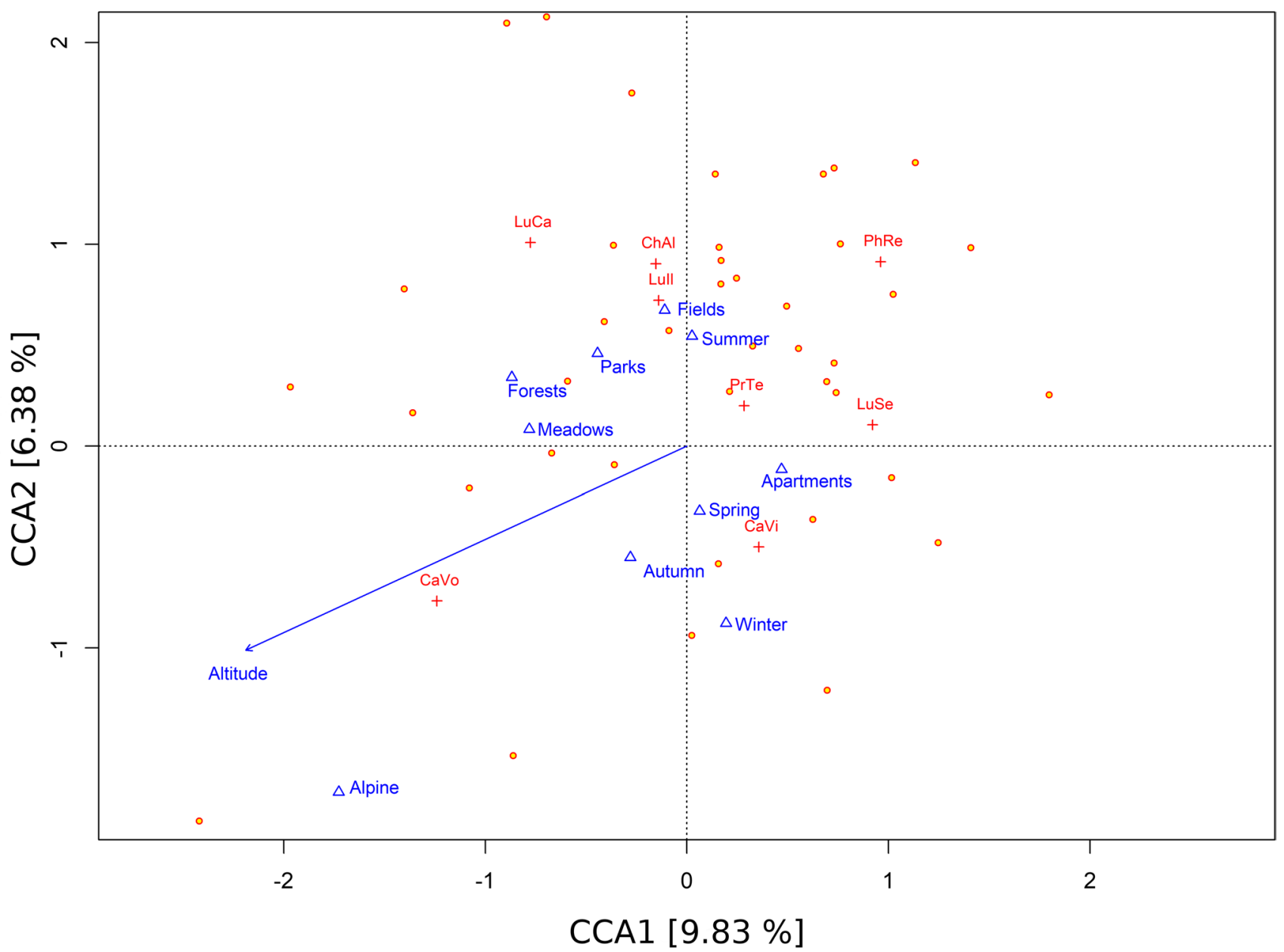

Fig. 2 CCA ordination triplot, cases are represented by circles, species by crosses and factors as triangles. Species names were abbreviated (Calliphora vicina (CaVi), Calliphora vomitoria $(\mathrm{CaVo})$, Chrysomya albiceps (ChAl), Lucilia caesar (LuCa), Lucilia illustris (LuIl),
Lucilia sericata (LuSe), Phormia regina (PhRe), Protophormia terraenovae (PrTe)). Amount of explained variability represented by $\mathrm{CCA}$ axes is given in square brackets
Fig. 3 Histogram of monthly distribution of real case investigations during 1993-2007

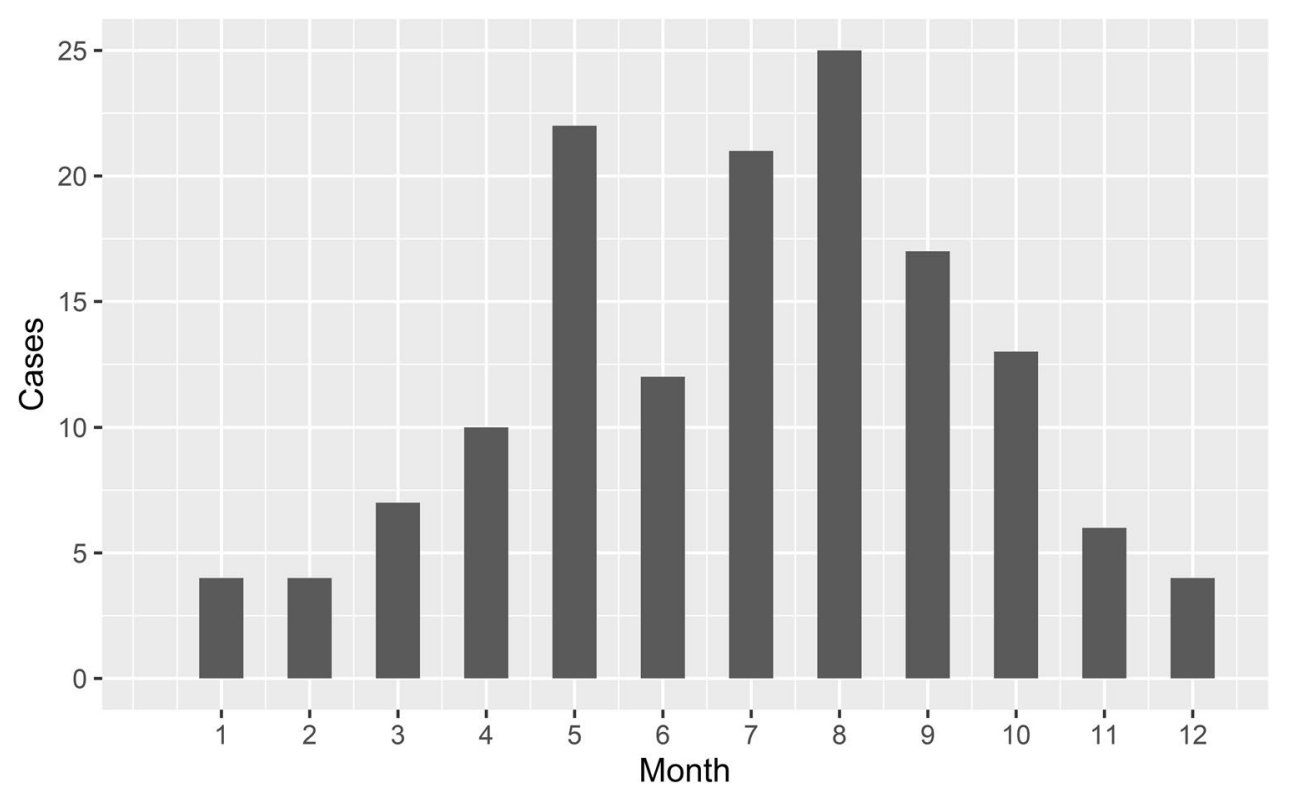


Table 1 The comparison of the species occurrence in real case investigations in Lausanne (1993-2007) and Frankfurt (2014-2016) (expressed as a percentage of occurrences)

\begin{tabular}{lllll}
\hline Species & $\begin{array}{l}\text { N. of cases (Hode- } \\
\text { cek \& Jakubec) }\end{array}$ & $\begin{array}{l}\text { Percentage (Hode- } \\
\text { cek \& Jakubec) }\end{array}$ & $\begin{array}{l}\text { N. of cases } \\
\text { (Bernhardt } \\
\text { et al.) }\end{array}$ & $\begin{array}{l}\text { Percentage } \\
\text { (Bernhardt } \\
\text { et al.) }\end{array}$ \\
\hline Calliphora vicina & 100 & 68.97 & 22 & 43.14 \\
Lucilia sericata & 44 & 30.34 & 44 & 86.27 \\
Calliphora vomitoria & 42 & 28.97 & 12 & 23.53 \\
Lucilia caesar & 39 & 26.90 & 10 & 19.61 \\
Lucilia illustris & 23 & 15.86 & & \\
Protophormia terrae-novae & 21 & 14.48 & 16 & 31.37 \\
Chrysomya albiceps & 13 & 8.97 & 5 & 9.80 \\
Phormia regina & 7 & 4.83 & 22 & 43.14 \\
Cynomya mortuorum & 2 & 1.38 & 0 & 0.00 \\
Lucilia ampullacea & 1 & 0.69 & 23 & 45.10 \\
Total cases & $\mathbf{1 4 5}$ & & $\mathbf{5 1}$ & \\
\hline
\end{tabular}

In Bernhardt et al. (2018) comparative study, L. caesar and L. illustris were not differentiated
The CCA analysis was able to explain $19.98 \%$ of the total variability ( 0.534 out of 2.672 inertia value) while first (inertia $=0.263$ ) and second $(0.170)$ canonical axes were responsible for explaining 9.834 and $6.375 \%$ of total variation respectively. Its results show that all environmental factors (altitude, season, and habitat type) prove to be significantly associated with the occurrences of observed blowflies $(p$-value $<0.001)$. Specifically, altitude $(F$ value $=8.382 ; \mathrm{Df}=1 ; p$ value $<0.001)$, season $(F$ value $=3.312$; $\mathrm{Df}=3 ; p$ value $<0.001)$ and habitat type $(F$ value $=3.377$ $\mathrm{Df}=5 ; p$ value $<0.001)$. Cynomia vomitoria shows a high correlation with the increasing altitude and also with colder parts of the year (autumn and winter) (Fig. 2). This can be further seen in Fig. $4 \mathrm{~b}$ as the second peak of activity occurs in September and October and the species was observed also in all winter months except February.

GLMM analysis showed a significant change of presence with altitude only in the case of $C$. vomitoria $(Z$ value $=$ 4.203, $p$ value $<0.001)$ and $L$. caesar $(Z$ value $=2.551$, p-value $=0.011)$; however, more species seemed to be affected by altitude (Figs. 5 and 6). Calliphora vicina was the only other species correlated with the cold seasons and partially also higher altitudes (Figs. 2, 5, and 6). While C. vomitoria preferred the natural environment, $C$. vicina was mostly species of indoor cases and it could be found throughout the whole year (Figs. 4a and 7). The secondmost dominant species-L. sericata - was found regularly in anthropogenic habitats, i.e., apartments, fields, and parks (Fig. 7). However, unlike C. vicina, its peak activity was recorded in summer (Fig. 4g). Protophormia terraenovae and $P$. regina were correlated with low altitudes with the peak of their activity in August (Figs. 4c-d, 5, and 6) $(P$. regina was the least common species in our analyses with only 7 observations). Lucilia caesar and L. illustris were found in all biotopes except alpine; however, L. caesar was found mostly in natural environments with the most observations in forest habitat, while L. illustris correlated with the habitat type park and field (Figs. 2 and 7). All species of the genus Lucilia seemed to prefer summer season and lower altitudes, except one observation of $L$. caesar at 1650 $\mathrm{m}$ above sea level (Figs. 4e-g, 5, and 6). Chrysomya albiceps was another summer species mostly active in August; however, there were 2 cases with this species present also in February and April (as live pupae) (Fig. 4h). The habitat preference of $C$. albiceps was not significant. While it was often found in environments as meadows and forests, there were some observations in the apartments as well (Fig. 7). The altitudinal distribution was similar to that of P. terraenovae with one occurrence at $1230 \mathrm{~m}$ above sea level (Figs. 5 and 6).

\section{Discussion}

This study is the first research using a large dataset of real cases for systematic study with a focus on the spatio-temporal and altitudinal distribution of blowflies in Switzerland. All 10 species of the family Calliphoridae, which were present on the bodies, belong among common necrophagous European fauna. The most common species of our dataset was by far C. vicina (69\%), while in some other ecological studies from Switzerland or Germany first place often belongs to $L$. sericata $[3,12,34]$. In our case, $L$. sericata was present in $30 \%$ of cases (while still being the secondmost dominant species of our dataset). The occurrence of $L$. sericata and some other focal species is surprisingly different in comparison with a similar dataset of Bernhardt et al. [3], who analyzed the Diptera assemblages of 51 human remains in the city of Frankfurt. The biggest discrepancies between the two datasets were among the following species: 
Fig. 4 a-h Histograms depicting the monthly distribution of records of occurrence of all stages for each species of family Calliphoridae (species with less than 5 records were excluded)
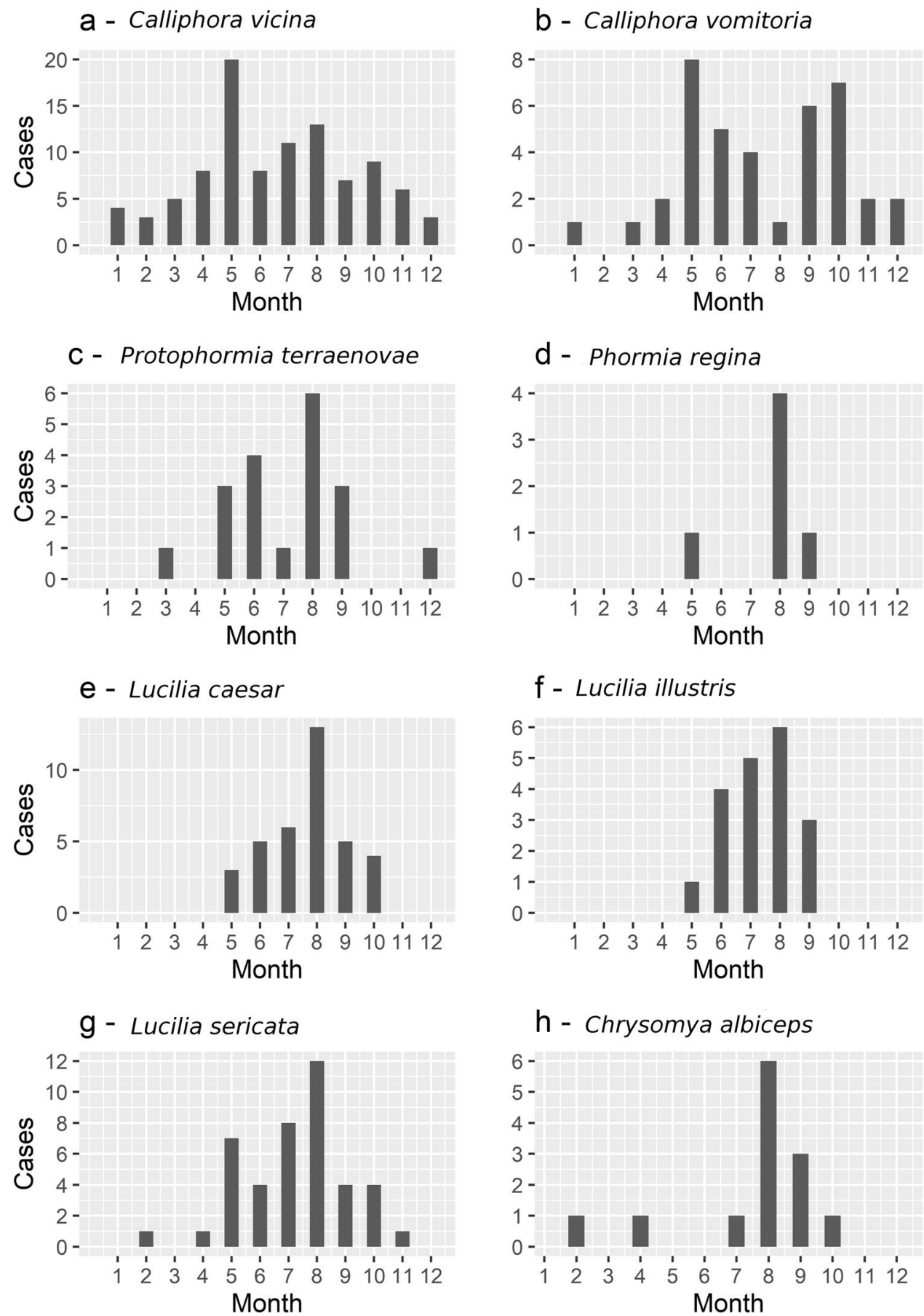

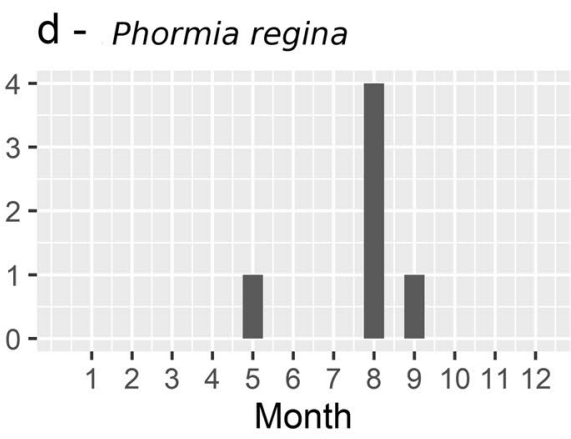

f - Lucilia illustris

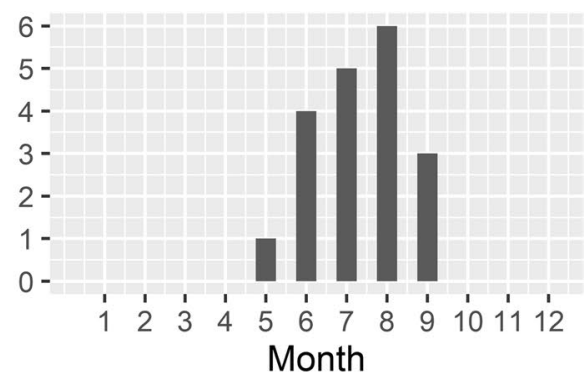

h - Chrysomya albiceps

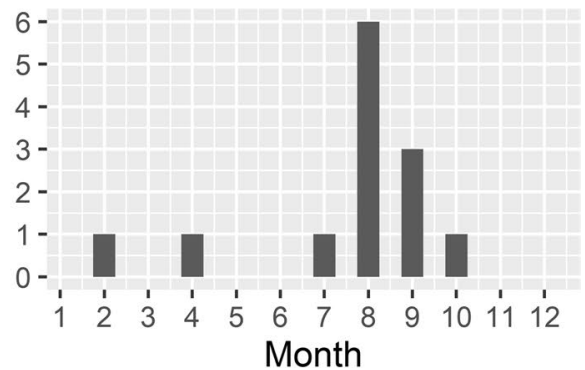

L. sericata (30\% vs. $86 \%$ ), P. regina (5\% vs. $43 \%$ ), and $L$. ampullacea (1\% vs. $45 \%)$ (Table 1). Some of the reasons for such substantial differences can be the different years of sampling (1993-2007 in our case vs. 2014-2016 in Bernhardt's dataset) or the proportion of indoor vs. outdoor cases. There were only 9 out of 51 cases (i.e., $18 \%$ ) found outdoor in Frankfurt [3], while we localized 58 out of 145 cases (i.e., $39 \%$ ) outdoor in and around Lausanne. The geographical distribution of P. regina and L. ampullacea in Europe during the years 1993-2007 could also be different from recent years due to climate change $[27,35,36]$. However, we think that the most probable reason might be the character of the local habitat composition and the topography of the compared areas. While Lausanne is situated $495 \mathrm{~m}$ above sea level surrounded by high mountains, Frankfurt is a low altitude city (112 $\mathrm{m}$ above sea level). If we take the altitude as a surrogate of the climate, we can assume that higher altitudes will be more suitable for cold-tolerating species like C. vicina, while lower altitudes fit better the thermophilous species such as $L$. sericata. 


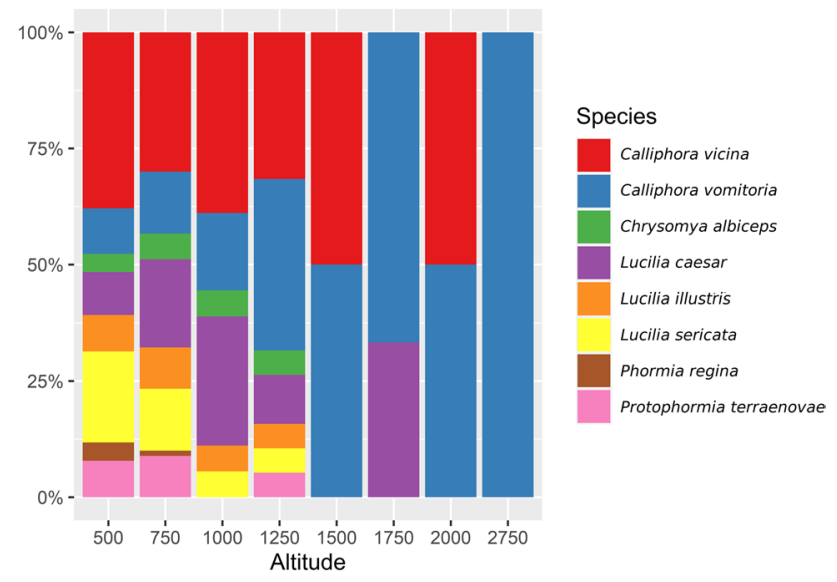

Fig. 5 Species composition of Calliphoridae at different altitudinal intervals (expressed as a percentage of occurrences)

\section{Altitudinal gradient}

Due to the local topography, the cases described herein are ranging from $287 \mathrm{~m}$ above sea level up to $2620 \mathrm{~m}$ above sea level (Fig. 5). Such a large altitudinal gradient allowed us to evaluate the ability of blowflies to breed and inhabit high mountain habitats. The knowledge of the blowfly distribution along the altitudinal gradient can be an important information as it can contribute to the understanding of the geographical distribution of many species as well as their local diversity [37]. There were only 3 species able to colonize human remains above $1500 \mathrm{~m}$ : C. vomitoria, C. vicina, and L. caesar. These results are in agreement with the results of [38], who studied the distribution of blowflies along an altitudinal gradient in central Spain. Baz et al. [38] determined C. vomitoria and $C$. vicina as species of high altitudes (most abundant in between 1600-1800 m), while L. caesar as a species of intermediate elevations. Unfortunately, there were only 7 bodies localized outside in high altitudes (above 1200 $\mathrm{m})$. Calliphora vomitoria was present in all of the cases, $C$. vicina was present in 3 cases, and L. caesar in 1 case. Even with such a small amount of appearances in the highest altitudes, the affinity to altitude was significant for $L$. caesar and $C$. vomitoria as the trend was set in lower altitudes. Calliphora vomitoria is a thermophobic species [12, 39], which could explain its altitudinal preferences if we consider elevational gradient as a surrogate of climate [38]. Indeed, the temperature profile in high elevations will always be one of the limiting factors, which means that thermophilous species will visit higher altitudes only occasionally during the warmest days of the year. The occurrence of the thermophilous species in high elevations is thus also season dependent as the upper distributional limits of species may fluctuate on a seasonal or annual basis $[40,41]$. All other species in our dataset preferred low elevations. The affinity to low altitudes is not surprising for thermophilous species such as L. sericata and C. albiceps (in fact, no species of Lucilia was able to pass $1200 \mathrm{~m}$ except for $L$. caesar). However, unlike L. sericata, C. albiceps is occasionally capable of reaching high elevations [38]. The highest locality where $C$. albiceps was present in our dataset was at $1230 \mathrm{~m}$, where 2 living pupae were found in the forest. Phormia regina is the only species, which did not pass the altitude of $750 \mathrm{~m}$. Our data thus suggest a strong negative correlation to altitude. However, since $P$. regina was also the least observed species of our analyses, the results of its altitudinal gradient might be incomplete. Indeed, the presence of $P$. regina was already reported as high as $2835 \mathrm{~m}$ on remains of a human stillborn infant [42] and up to $3566 \mathrm{~m}$ on rabbit carcasses [43] (both cases from Colorado). The local altitudinal distribution of this species in Switzerland should be further monitored to complete the missing data and confirm its presence in higher elevations.

\section{Habitat preference}

The habitat preferences of all 8 analyzed species are shown in Fig. 2 as well as in Fig. 6. The results generally confirm the ecology of detected species known from previous experiments conducted in Europe. Calliphora vicina and $L$. sericata preferred apartments (i.e., indoor cases), which is supported by the results of many other authors [3, 44-46]. Calliphora vicina was present in $42 \%$ of indoor cases, which makes it the most important species from the point of forensic investigations of indoor cases in and around Lausanne. Lucilia sericata was often found also in the fields or parks near human settlements. The distribution of $L$. sericata in our study is therefore mostly synanthropic, which is similar to the findings of $[4,47]$. On the contrary, C. vomitoria is considered an indicator of natural environments [4, 47, 48] and rural sites [34]. The occurrence of $C$. vomitoria in our area was distributed among all observed habitats, with a preference for meadows, forests, and alpine habitats. Such broadscale of distribution excludes this species as a biogeographic indicator [21]. The distribution of $C$. vomitoria was partially copied by the occurrence of $L$. caesar. Lucilia caesar also prefers shaded locations in rural environments [12, $21,47]$ and it was positively correlated with forest habitats. However, even L. caesar was found 13 times (15\%) in the apartments. The explanation probably is the overall majority of the indoor cases in our dataset (Table 2). As mentioned above, $61 \%$ of all the cases were found in the apartments. All analyzed species of blowflies were found indoor (Fig. 7). Lucilia illustris was significantly related to parks and fields, i.e., in more synanthropic habitats than those preferred by L. caesar. The habitat preference and synanthropic level for $L$. illustris are somehow in between $L$. sericata and $L$. caesar. It is a heliophilic species less abundant in the shady 
Fig. 6 Prediction of the mean probability of occurrence $(0-100)$ with standard errors across altitudes based on GLMM binomial model for all analyzed species

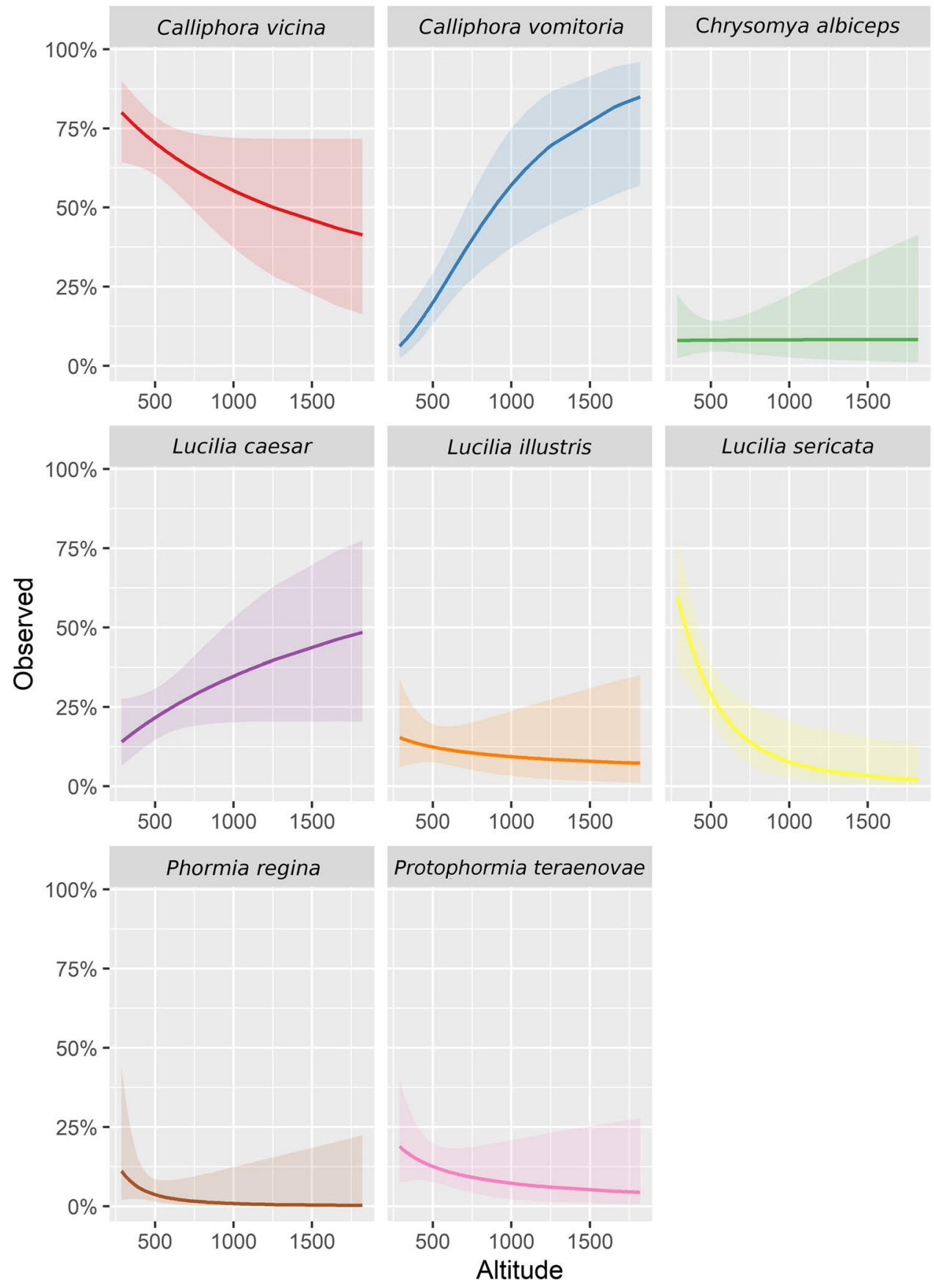

forest localities (in comparison to L. caesar) as well as in the indoor cases (in comparison with L. sericata) [4, 12]. It has to be noted that the identification of $L$. caesar and $L$. illustris can be tricky even in adult stages, which can lead to a certain bias in results or even omittance of the species differentiation for certain analyses [3]. The non-indigenous blowfly $C$. albiceps is often described as tropical and subtropical species; however, its occurrence in Europe is already well established and it serves as a forensically important indicator for European criminal investigations for years $[21,49]$. Its occurrence on human remains in and around
Lausanne was rather occasional with some tendencies to prefer more natural habitats as forests and meadows. Recent data however show a bigger percentual proportion of this species on human cadavers, which can point at its increasing importance as a species of forensic importance in Switzerland (data of real cases from 2019 to 2020 in Lausanne Hodecek unpublished). The rest of the observed species did not show any significant dependence on habitat type. This includes $P$. regina with only 7 observations and $P$. terraenovae, which was present in all habitat types except fields and alpine environment. 


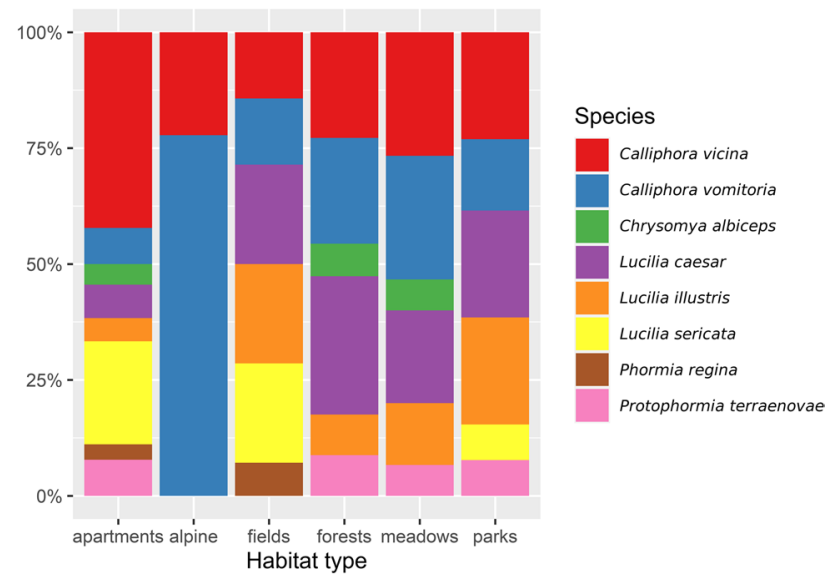

Fig. 7 Species composition of Calliphoridae in each recognized habitat (expressed as a percentage of occurrences)

Table 2 The number of real case investigations in each habitat type during 1993-2007

\begin{tabular}{lll}
\hline Habitat type & No. of cases & Percentage \\
\hline Field & 7 & 4.83 \\
Forest & 31 & 21.38 \\
Alpine & 7 & 4.83 \\
Meadow & 7 & 4.83 \\
Park & 5 & 3.45 \\
Apartment & 88 & 60.69 \\
Total & $\mathbf{1 4 5}$ & $\mathbf{1 0 0}$ \\
\hline
\end{tabular}

\section{Seasonal distribution}

The seasonal occurrence of blowflies in Europe has already been studied in several experiments (Portugal [50]; Spain [6, 48]; England [4]; Germany [34]; Switzerland [12]; Italy [47]). However, the activity of geographically distant populations within the same species can differ due to their local adaptations [51-53]. It is thus very important to monitor the activity of the forensically important blowflies locally. In our dataset, there was only one species with occurrence in each month-C. vicina. It is a species well adapted for cold weather and during the winter season, it is often the only species found on the bodies [34]. In southern parts of Europe, it can be missing during the warm part of the year due to its upper developmental threshold of $30^{\circ} \mathrm{C}$ [47, 50]. Calliphora vomitoria was active during the whole year except February. Both species are thermophobic with supercooling points (SCP) of $-8^{\circ} \mathrm{C}(C$. vicina $)$ and $-11^{\circ} \mathrm{C}(C$. vomitoria) for overwintering adult flies [39]. The SCP is higher for C. vicina; however, due to its preference for urban habitats, it can stay active even in the coldest winters with many opportunities for warm refuges [4]. The occurrence of all other species was focused to warm summer and autumn months. Such results are supported also by [4, 12, 34, 48]. Thermophilous species of genus Lucilia were mostly present in August with the highest activity from May to October. Only $L$. sericata occurred also during the cold months of February and November; however, all of these cases were located indoors. Interestingly, live pupae were found in the case from February 1997 and the PMI $_{\text {min }}$ was calculated to be 63 days, which would mean an oviposition at the end of December. Even though L. sericata is considered to be a "summer" species, it can occasionally be active even during the winter months when it seeks the warmth of human settlements. Similar to $C$. vicina, this species is also related to urban areas. All species except $C$. vicina and $C$. vomitoria were the most active during August; however, this is likely supported by the fact that August was the busiest month for the police investigators (Fig. 3). Chrysomya albiceps and $P$. terraenovae were irregularly distributed during the year with a peak of their activity in summer.

There was, however, a case with living pupae of $P$. terraenovae found in December 1997 in the forest. The $\mathrm{PMI}_{\min }$ for this case was estimated to be 105 days, which would mean oviposition at the beginning of September. Some living pupae of $C$. albiceps were also found during cold months of February and April 1996 in forested areas. The $\mathrm{PMI}_{\min }$ was calculated to be more than 6 months for both cases, which means that pupae of $C$. albiceps could be able to overwinter and survive very low temperatures. While $P$. terraenovae is considered a cold-tolerating species [20,54], C. albiceps is a strictly thermophilous species $[41,49,55]$; therefore, such findings are an interesting observation. Phormia regina was found only in May, August and September, but the seasonal activity cannot be determined just from 7 occurrences.

\section{The study limitations}

Similar to other studies evaluating insect data from real cases, it is important to note that they do not represent the results of a planned ecological study and while such a dataset has certain advantages, we have to be also aware of its disadvantages [19]. One of the most important differences between data collected during carefully designed experiments and real case scenarios is that we will never be able to retrieve the same amount of replications out of the latter. For example, in the presented dataset $61 \%$ of cases were found indoor, while only $39 \%$ were outdoor. This is a typical scenario as most cases of legal investigations are conducted on bodies found inside [3]. In this article, we also decided to analyze the habitat preferences of the focal species. Due to the majority of cases being located inside, the most numerous habitat types in our dataset was "apartment" with 88 cases, while only 5 bodies were found in parks (Table 2). The same applies for the altitudinal distribution as most of 
Table 3 The number of real case investigations for each altitudinal range during 1993-2007

\begin{tabular}{lll}
\hline Altitude range & No. of cases & Percentage \\
\hline $0-500$ & 77 & 53.10 \\
$500-750$ & 46 & 31.72 \\
$750-1000$ & 9 & 6.21 \\
$1000-1250$ & 8 & 5.52 \\
$1250-1500$ & 1 & 0.69 \\
$1500-1750$ & 2 & 1.38 \\
$1750-2000$ & 1 & 0.69 \\
$2000-2750$ & 1 & 0.69 \\
Total & $\mathbf{1 4 5}$ & $\mathbf{1 0 0}$ \\
\hline
\end{tabular}

the cases (77) were between 0 and $500 \mathrm{~m}$, while there was only 1 case between 2000 and $2750 \mathrm{~m}$ (Table 3). Due to the discrepancies between these variables, we could not compare them equally. Other not-tested variables as interspecific competition or potential presence and influence of xenobiotics were not taken into consideration.

\section{Conclusion}

The analyses of 160 real case investigations from Switzerland brought some new and interesting information about the spatio-temporal distribution of blowflies, while confirming some general expectations of their ecological requirements. The results are of a great importance for forensic entomologists and insect ecologists as they can directly help with the $\mathrm{PMI}_{\min }$ estimation and are easily comparable with similar data from all around the world. Indeed, the fact that the dataset consisted of blowflies collected during real case investigations increases the validity of the results as the bias of studies trying to simulate real cases is omitted here. Our study compared the Swiss dataset with a similar dataset from Germany and found unexpected differences in species composition and occurrences of certain species. Such differences stem from an intricate interplay between large-scale and local-scale processes [56] as well as colonization history [57] and they only underline the importance of knowing the local populations of necrophagous insects by a forensic entomologist. Every forensic entomologist should be aware of the spatio-temporal and altitudinal distribution of necrophagous insects in the area of their activity as it significantly precises the $\mathrm{PMI}_{\text {min }}$ estimation as well as other predictions and analyses forensic entomologist can face. From an ecological point of view, it is interesting to study the distribution of the species in Europe, their local adaptations, and reactions to global warming (latitudinal/altitudinal shifts). In order to obtain such results, we recommend monitoring the local populations of blowflies in and around Lausanne further and comparing recent observations with this dataset.

Acknowledgements We want to thank the Museum of Zoology in Lausanne and its director Prof. Michel Sartori for providing us with access to the collection and the dataset. Their help and support are greatly appreciated. We would like to thank Claude Wyss and Prof. Daniel Cherix for the material collection and preparation. We are also grateful for the comments and suggestions of Dr. Vincent Varlet before the manuscript's submission and for the English language checking done by Ndidi Hodeckova.

Funding Open access funding provided by University of Lausanne. This research did not receive any specific grant from funding agencies in the public, commercial, or not-for-profit sectors.

\section{Declarations}

Ethical approval All procedures performed in this study were in accordance with the ethical standards of the institutional and/or national research committee and the 1964 Helsinki declaration and its later amendments, or comparable ethical standards. The personal data of the deceased as their name and age were removed from the dataset before its analyses.

Conflict of interest The authors declare no competing interests.

Open Access This article is licensed under a Creative Commons Attribution 4.0 International License, which permits use, sharing, adaptation, distribution and reproduction in any medium or format, as long as you give appropriate credit to the original author(s) and the source, provide a link to the Creative Commons licence, and indicate if changes were made. The images or other third party material in this article are included in the article's Creative Commons licence, unless indicated otherwise in a credit line to the material. If material is not included in the article's Creative Commons licence and your intended use is not permitted by statutory regulation or exceeds the permitted use, you will need to obtain permission directly from the copyright holder. To view a copy of this licence, visit http://creativecommons.org/licenses/by/4.0/.

\section{References}

1. Amendt J, Richards CS, Campobasso CP et al (2011) Forensic entomology: applications and limitations. Forensic Sci Med Pathol 7:379-392. https://doi.org/10.1007/s12024-010-9209-2

2. Byrd JH, Tomberlin JK (2020) Insect of forensic importance. In: Byrd JH, Tomberlin JK (eds) Forensic entomol. Util. Arthropods Leg. Investig, 3rd edn. CRC Press, Boca Raton, pp 15-62

3. Bernhardt V, Bálint M, Verhoff MA, Amendt J (2018) Species diversity and tissue specific dispersal of necrophagous Diptera on human bodies. Forensic Sci Med Pathol 14:76-84. https://doi. org/10.1007/s12024-018-9947-0

4. Hwang C, Turner BD, Monitoring D, County C (2005) Spatial and temporal variability of necrophagous Diptera from urban to rural areas. Med Vet Entomol 19:379-391. https://doi.org/10.1111/j. 1365-2915.2005.00583.x

5. Davies L (1999) Seasonal and spatial changes in blowfly production from small and large carcasses at Durham in lowland northeast England. Med Vet Entomol 13:245-251 
6. Arias-Robledo G, Stevens JR, Wall R (2019) Spatial and temporal habitat partitioning by calliphorid blowflies. Med Vet Entomol 33:228-237. https://doi.org/10.1111/mve.12354

7. Vanin S, Tasinato P, Ducolin G et al (2008) Use of Lucilia species for forensic investigations in Southern Europe. Forensic Sci Int 177:37-41. https://doi.org/10.1016/j.forsciint.2007.10.006

8. Pohjoismäki JLO, Karhunen PJ, Goebeler S et al (2010) Indoors forensic entomology : colonization of human remains in closed environments by specific species of sarcosaprophagous flies. Forensic Sci Int 199:38-42. https://doi.org/10.1016/j.forsciint. 2010.02.033

9. Bugelli V, Forni D, Bassi LA et al (2015) Forensic entomology and the estimation of the minimum time since death in indoor cases. J Forensic Sci 60:525-531. https://doi.org/10.1111/15564029.12647

10. Vasconcelos SD, Barbosa TM, Oliveira TPB (2015) Diversity of forensically-important dipteran species in different environments in Northeastern Brazil, with notes on the attractiveness of animal baits. Florida Entomol 98:770-775. https://doi.org/10.1653/024. 098.0256

11. Klong-klaew T, Ngoen-klan R, Moophayak K et al (2018) Spatial distribution of forensically significnat blow flies in subfamily Luciliinae (Diptera: Calliphoridae), Chiang Mai Province, Northern Thailand: observations and modeling using GIS. Insects 9:181. https://doi.org/10.3390/insects9040181

12. Feddern N, Amendt J, Schyma C et al (2018) A preliminary study about the spatiotemporal distribution of forensically important blow flies (Diptera: Calliphoridae) in the area of Bern, Switzerland. Forensic Sci Int 289:57-66. https://doi.org/10.1016/j.forsc iint.2018.05.022

13. Mozaffari E, Saghafipour A, Arzamani K et al (2020) Direct injury, myiasis, forensics geographical distribution, biodiversity, and species richness of medically important necrophagous flies in central Iran. 57:377-381. https://doi.org/10.1093/jme/tjz203

14. Babcock NJ, Pechal JL, Benbow ME (2020) Adult blow fly (Diptera: Calliphoridae) community structure across urban-rural landscapes in Michigan, United States. J Med Entomol 57:705-714. https://doi.org/10.1093/jme/tjz246

15. Moretti T d C, Bonato V, Godoy WAC (2011) Determining the season of death from the family composition of insects infesting carrion. Eur J Entomol 108:211-218. https://doi.org/10.14411/ eje.2011.029

16. Harvey M, Gasz N, Woolley Z et al (2019) Dipteran attraction to a variety of baits : implications for trapping studies as a tool for establishing seasonal presence of significant species. 56:12831289. https://doi.org/10.1093/jme/tjz050

17. Vilte R, Gleiser RM, Horenstein MB (2020) Necrophagous fly assembly: evaluation of species bait preference in field experiments. J Med Entomol 57:437-442. https://doi.org/10.1093/jme/ tjz192

18. Boudreau DR, Hammami N, Moreau G (2021) Environmental and evolutionary factors favouring the coexistence of sarcosaprophagous Calliphoridae species competing for animal necromass. Ecol Entomol 1-8. https://doi.org/10.1111/een.13076

19. Sanford MR (2017) Insects and associated arthropods analyzed during medicolegal death investigations in Harris County, Texas, USA: January 2013-April 2016. PLoS One 12:1-23. https://doi. org/10.1371/journal.pone.0179404

20. Greenberg B, Tantawi TI (1993) Different developmental strategies in two boreal blow flies (Diptera: Calliphoridae). J Med Entomol 30:481-484. https://doi.org/10.1093/jmedent/30.2.481

21. Grassberger M, Frank C (2004) Initial study of arthropod succession on pig carrion in a central European urban habitat. J Med Entomol 41:511-523. https://doi.org/10.1603/0022-2585-41.3. 511
22. Anderson GS (2011) Comparison of decomposition rates and faunal colonization of carrion in indoor and outdoor environments. J Forensic Sci 56:136-142. https://doi.org/10.1111/j.1556-4029. 2010.01539.x

23. Battán Horenstein M, Linhares AX (2011) Seasonal composition and temporal succession of necrophagous and predator beetles on pig carrion in central Argentina. Med Vet Entomol 25:395-401. https://doi.org/10.1111/j.1365-2915.2011.00969.x

24. Benbow ME, Lewis AJ, Tomberlin JK, Pechal JL (2013) Seasonal necrophagous insect community assembly during vertebrate carrion decomposition. J Med Entomol 50:440-450. https://doi.org/ 10.1603/ME12194

25. Schoenly KG, Haskell NH, Hall RD, Gbur JR (2007) Comparative performance and complementarity of four sampling methods and arthropod preference tests from human and porcine remains at the forensic anthropology center in Knoxville, Tennessee. J Med Entomol 44:881-894. https://doi.org/10.1603/0022-2585(2007) 44[881:CPACOF]2.0.CO;2

26. Dekeirsschieter J, Frederickx C, Verheggen FJ et al (2013) Forensic entomology investigations from Doctor Marcel Leclercq (1924-2008): a review of cases from 1969 to 2005. J Med Entomol 50:935-954. https://doi.org/10.1603/me12097

27. Lutz L, Zehner R, Verhoff MA et al (2021) It is all about the insects: a retrospective on 20 years of forensic entomology highlights the importance of insects in legal investigations. Int J Legal Med 135:2637-2651. https://doi.org/10.1007/ s00414-021-02628-6

28. Wyss C, Cherix D (2006) Traite d'Entomologie Forensique: Les Insectes sur la Scene de Crime, 1st edn. Presses Polytechniques et Universitaires de Romandes, Lausanne

29. Cherix D, Wyss C, Pape T (2012) Occurrences of flesh flies (Diptera: Sarcophagidae) on human cadavers in Switzerland, and their importance as forensic indicators. Forensic Sci Int 220:158-163. https://doi.org/10.1016/j.forsciint.2012.02.016

30. Szpila K (2012) Key for identification of European and Mediterranean blowflies (Diptera, Calliphoridae) of forensic importance - adult flies. In: Gennard D (ed) Forensic Entomol. An Introd, 2nd edn. Willey-Blackwell, Chichester, pp 77-81

31. Google (2021) Google Earth Pro. (archive of historical maps). Switzerland (canton of Vaud, canton of Geneva, canton of Fribourg, canton of Valais and canton of Ticino), Eye alt $36 \mathrm{mi}$. Borders and labels; places layers. NOAA, DigitalGlobe 2013. https://www.google.com/earth/. Accessed February 2021

32. Oksanen J, Blanchet FG, Friendly M et al (2019) vegan: Community Ecology Package

33. R Core Team (2020) R: A Language and Environment for Statistical Computing [program]. https://www.r-project.org/. Accessed March 2021

34. Fremdt H, Amendt J (2014) Species composition of forensically important blow flies (Diptera: Calliphoridae) and flesh flies (Diptera: Sarcophagidae) through space and time. Forensic Sci Int 236:1-9. https://doi.org/10.1016/j.forsciint.2013.12.010

35. Halsch CA, Shapiro AM, Fordyce JA et al (2021) Insects and recent climate change. Proc Natl Acad Sci U S A 118:1-9. https://doi.org/10.1073/PNAS.2002543117

36. Turchetto M, Vanin S (2004) Forensic entomology and climatic change. Forensic Sci Int 168:S207-S209. https://doi.org/10. 1016/j.forsciint.2004.09.064

37. Ya'Cob Z, Takaoka H, Pramual P et al (2016) Distribution pattern of black fly (Diptera: Simuliidae) assemblages along an altitudinal gradient in Peninsular Malaysia. Parasit Vectors 9:1-17. https://doi.org/10.1186/s13071-016-1492-7

38. Baz A, Cifrián B, Díaz-Aranda LM, Martín-Vega D (2007) The distribution of adult blow-flies (Diptera: Calliphoridae) along an altitudinal gradient in Central Spain. Ann Soc Entomol Fr 43:289-296. https://doi.org/10.1080/00379271.2007.10697524 
39. Block W, Erzinclioglu YZ, Worland MR (1990) Cold resistance in all life stages of two blowfly species (Diptera, Calliphoridae). Med Vet Entomol 4:213-219. https://doi.org/10.1111/j.13652915.1990.tb00279.x

40. Hodkinson ID (2005) Terrestrial insects along elevation gradients: species and community responses to altitude. Biol Rev Camb Philos Soc 80:489-513. https://doi.org/10.1017/S1464 793105006767

41. Lambiase S, Camerini G (2012) Spread and habitat selection of Chrysomya albiceps (Wiedemann) (Diptera Calliphoridae) in Northern Italy: forensic implications. J Forensic Sci 57:799801. https://doi.org/10.1111/j.1556-4029.2011.02027.x

42. Adair TW (1999) Three species of blowfly (Diptera: Calliphoridae) collected from a human stillborn infant in the rocky mountains of Colorado. J Med Entomol 36:236-237

43. De Jong GD, Chadwick JW (1999) Decomposition and arthropod succession on exposed rabbit carrion during summer at high altitudes in Colorado, USA. J Med Entomol 36:833-845

44. Schumann H (1990) The occurence of Diptera in living quarters. Angew Parasitol 31:131-141

45. Reibe S, Madea B (2010) How promptly do blowflies colonise fresh carcasses? A study comparing indoor with outdoor locations. Forensic Sci Int 195:52-57. https://doi.org/10.1016/j.forsc iint.2009.11.009

46. Martín-Vega D, Díaz-Aranda LM, Baz A, Cifrián B (2017) Effect of temperature on the survival and development of three forensically relevant dermestes species (Coleoptera: Dermestidae). J Med Entomol 54:1140-1150. https://doi.org/10.1093/jme/tjx110

47. Greco S, Brandmayr P, Bonacci T (2014) Synanthropy and temporal variability of Calliphoridae living in Cosenza. 1-5. https:// doi.org/10.1093/jisesa/ieu078

48. Zabala J, Díaz B, Saloña-Bordas MI (2014) Seasonal blowfly distribution and abundance in fragmented landscapes. Is it useful in forensic inference about where a corpse has been decaying? PLoS One 9:e99668. https://doi.org/10.1371/journal.pone.0099668

49. Grassberger M, Friedrich E, Reiter C (2003) The blowfly Chrysomya albiceps (Wiedemann) (Diptera: Calliphoridae) as a new forensic indicator in Central Europe. Int J Legal Med 117:75-81. https://doi.org/10.1007/s00414-002-0323-x

50. Prado E, Castro C, Serrano A, Martins Da Silva P, García MD (2012) Carrion flies of forensic interest: a study of seasonal community composition and succession in Lisbon, Portugal. Med Vet Entomol 26:417-431. https://doi.org/10.1111/j.1365-2915. 2012.01031.x

51. Balashov SV, Kipyatkov VE (2008) Study of intrapopulational variability of duration and temperature norms of development of the linden bug Pyrrhocoris apterus (Heteroptera, Pyrrhocoridae). J Evol Biochem Physiol 44:687-697. https://doi.org/10.1134/S0022 093008060069

52. Lopatina EB, Kipyatkov VE, Balashov SV et al (2012) Interspecific and intraspecific variation of the duration and thermal requirements for egg development in carabid beetles (Coleoptera, Carabidae) in the North-West of Russia. Entomol Rev 92:32-45. https://doi.org/10.1134/S0013873812010034

53. Moraiti CA, Nakas CT, Papadopoulos NT (2017) Local adaptation, intrapopulation adult emergence patterns, sex and prolonged diapause regulate the rate of postwinter development in pupae of the European cherry fruit fly. Biol J Linn Soc 121:282-293. https://doi.org/10.1093/BIOLINNEAN/BLW042

54. Warren JA, Anderson GS (2013) The development of Protophormia terraenovae (Robineau-Desvoidy) at constant temperatures and its minimum temperature threshold. Forensic Sci Int 233:374-379. https://doi.org/10.1016/j.forsciint.2013.10.012

55. Richards CS, Paterson ID, Villet MH (2008) Estimating the age of immature Chrysomya albiceps (Diptera: Calliphoridae), correcting for temperature and geographical latitude. Int J Legal Med 122:271-279. https://doi.org/10.1007/s00414-007-0201-7

56. Menge BA, Olson AM (1990) Role of scale and environmental factors in regulation of community structure. Trends Ecol Evol 5:52-57

57. Chang C, Marshall DJ (2017) Quantifying the role of colonization history and biotic interactions in shaping communities -a community transplant approach. Oikos 126:oik.03478. https://doi.org/ 10.1111/oik.03478

Publisher's note Springer Nature remains neutral with regard to jurisdictional claims in published maps and institutional affiliations. 